\title{
A Sequential Process for Manufacturing Nature-Inspired Anisotropic Superhydrophobic Structures on AISI 316L Stainless Steel
}

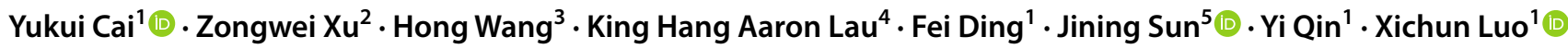

Received: 18 May 2019 / Revised: 24 July 2019 / Accepted: 30 July 2019 / Published online: 28 August 2019

(c) The Author(s) 2019

\begin{abstract}
Surfaces with anisotropic superhydrophobicity have great potential applications in drug delivery and microfluidic devices due to their unique properties of drag reduction and unidirectional fluid transportation. Observations of natural biological surfaces have proven that directional microstructures are indispensable for realizing anisotropic superhydrophobicity. However, current lithography-based manufacturing approaches have limited capabilities to scale-up for real-world industrial applications. This paper proposes a sequential process of laser ablation and chemical etching, for the first time, to manufacture ratchet-like microstructures on AISI 316L stainless steel by harvesting the advantages of both methods. The laser ablation will form a specified recast layer that will be covered by an oxide layer on the specimen, and these two layers can be easily removed in the chemical etching process to obtain the periodic ratchet-like microstructures. According to the experimental results, the direction of the microstructures is determined by the laser beam feed direction. Both the width and depth of microstructures increase with increasing laser power, which results in the disappearance of ridges. However, the increasing pitch will lead to the ridges appearing again. The specimen with a pitch of $25 \mu \mathrm{m}$ machined at a laser power of $20 \mathrm{~W}$ has a maximum contact angle of $158.2^{\circ}$. Moreover, with a dip angle of $7^{\circ}$, this specimen shows a strong anisotropic superhydrophobicity, the droplet easily rolls off the surface in the laser beam feed direction; however, it is pinned tightly in the opposite direction.
\end{abstract}

Keywords Laser ablation $\cdot$ Chemical etching $\cdot$ Superhydrophobic surface

Xichun Luo

xichun.luo@strath.ac.uk

Yukui Cai

Yukui.cai@strath.ac.uk

Jining Sun

Jining.Sun@hw.ac.uk

Yi Qin

qin.yi@strath.ac.uk

1 Centre for Precision Manufacturing, DMEM, University of Strathclyde, Glasgow, UK

2 State Key Laboratory of Precision Measuring Technology and Instruments, Centre of MicroNano Manufacturing Technology, Tianjin University, Tianjin, People's Republic of China

3 School of Materials Science and Engineering, Tianjin Polytechnic University, Xiqing, People's Republic of China

4 WestCHEM/Department of Pure and Applied Chemistry, University of Strathclyde, Glasgow, UK

5 School of Engineering and Physical Science, Heriot-Watt University, Edinburgh, UK

\section{Introduction}

Natural biological surfaces, such as lotus leaf, rice leaf, fish scale, and butterfly wings have attracted so much attention over the last few decades, mainly due to special wettability that formed during long-time evolution and natural selection. Surface with anisotropic hydrophobicity can realize unidirectional droplet transportation, which has tremendous applications for flow control, liquid transport, cell directing, drug delivery, and microfluidic devices [1-5].

The natural surfaces that possess capabilities of transporting liquid directionally exist in rice leaf, ryegrass leaf, spider silk, shorebird's beak, butterfly wing, desert beetle, Nepenthes peristome, and cactus spine [6, 7].

For example, the rice leaf has a large number of hierarchical structures on its surface. The average diameter of protrusions is around 5-8 $\mu \mathrm{m}$ but distributed along the direction that parallels to the edge [8-10]. Hence, the sliding angles of rice leaf are different in two directions (e.g., $4^{\circ}$ in the direction that parallels to the edge, $12^{\circ}$ in the direction that perpendicular to the edge) due to the anisotropic distribution 
of micro/nano structures [8-10]. The ryegrass leaf is another typical surface with the property of directional shedding-off of water, primarily due to their taper-ratchets in a periodic stripe-style array [11]. Guo found that the reversible release and pinning of liquids at solid-liquid interfaces in the process of drop moving is the underlying mechanism to achieve characteristic directional water shedding-off [11]. All of the above phenomena rely on taper-ratchets that have an open apex angle and tilt up slightly, which results in a gradient of retention at solid-liquid interfaces along the orientation of tips [11].

A variety of insect wings have unique micro/nano structures that help them to survive in the extreme natural environment. A water droplet will roll off along one direction with a small rolling angle while it shows a pinned state along the opposite direction on a butterfly wing. The asymmetric microstructures of butterfly wings can lead to an unstable state of the water droplet and make it easily roll off along the radial direction away from the body [11, 12]. Bixler reported that butterfly wings possess unique surface properties that combine the anisotropic flow, superhydrophobicity, and low adhesion force with water $[1,13]$. The author also found that aligned shingle-like scales in butterfly wings provided anisotropic flow leading to low drag, while microgrooves on its top offered superhydrophobicity and low adhesion properties [13]. Liu et al.'s research concluded that unbalanced surface tension on static conditions and fog drops contract asymmetrically from the surface on dynamic conditions were the underlying mechanism for the directional flow of fog drops [4]. Therefore, directional microstructures are indispensable to realize anisotropic superhydrophobicity.

In addition to the research efforts devoted to exploring the mechanisms of anisotropic flow, there is also a growing effort to develop various manufacturing processes to synthesize surfaces with directional transport properties. The present primary manufacturing approaches include lithography, replica moulding, aqueous sol-gel and chemical reduction [12-17]. For instance, Guo et al. employed a soft lithography technique to replicate the taper-ratchet structure of natural ryegrass leaf on the polymer surface. The prepared samples displayed a robust property of directional water shedding-off [11]. Song et al. reproduced the porous hierarchical architecture of butterfly wings by using $\mathrm{SnO}_{2}$ through an aqueous sol-gel soakage process with the assistance of anhydrous
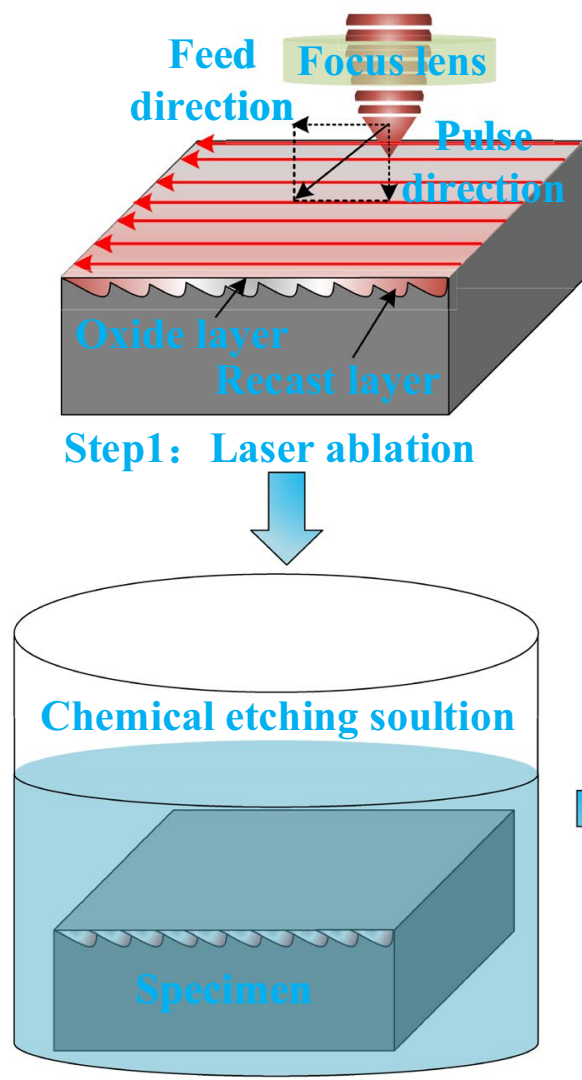

Step 2: Chemical etching

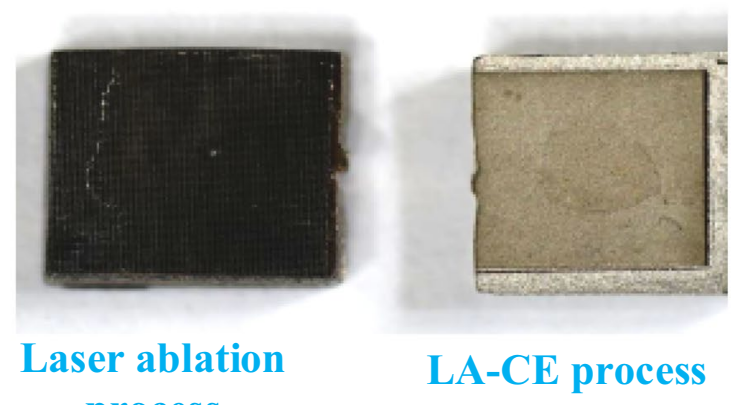

process

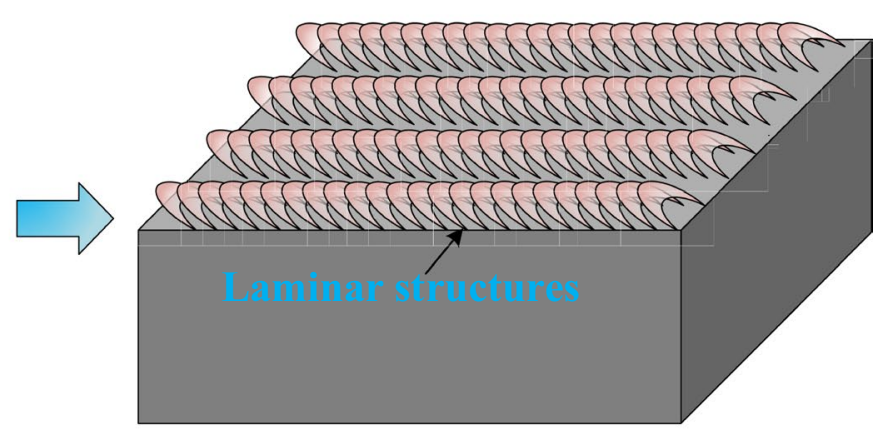

Step 3: Cleaning and surface energy reduction

Fig. 1 Schematic illustration of the manufacturing process of superhydrophobic ratchet structures 


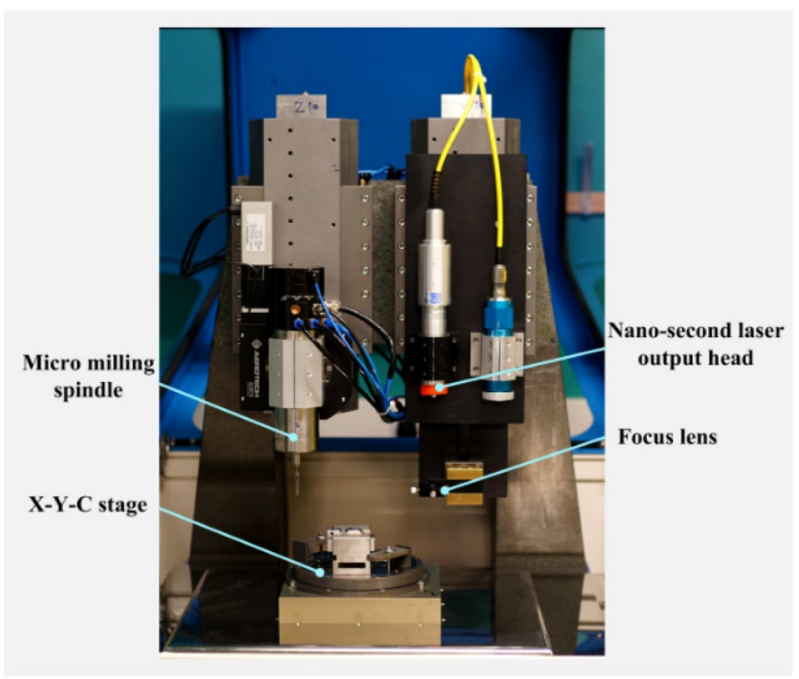

(a)

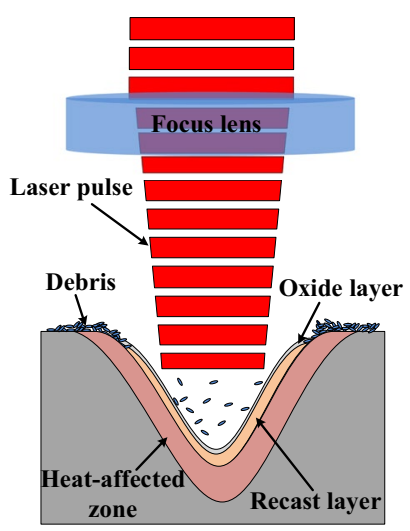

(b)

Fig. 2 Experimental setup for laser ablation trials. a The hybrid ultraprecision machine. b IPG fiber laser

Table 1 Operational conditions for experiments

\begin{tabular}{llllll}
\hline Number & Pitch $(\mu \mathrm{m})$ & $\begin{array}{l}\text { Laser } \\
\text { power } \\
(\mathrm{W})\end{array}$ & $\begin{array}{l}\text { Fre- } \\
\text { quency } \\
(\mathrm{kHz})\end{array}$ & $\begin{array}{l}\text { Feed rate } \\
(\mathrm{mm} / \\
\mathrm{min})\end{array}$ & Feed direction \\
\hline 1 & 25 & 10 & 20 & 30 & Unidirectional \\
2 & 25 & 15 & 20 & 30 & Unidirectional \\
3 & 25 & 20 & 20 & 30 & Unidirectional \\
4 & 25 & 20 & 20 & 30 & Bidirectional \\
5 & 50 & 10 & 20 & 30 & Unidirectional \\
6 & 50 & 15 & 20 & 30 & Unidirectional \\
7 & 50 & 20 & 20 & 30 & Unidirectional \\
\hline
\end{tabular}

ethanol [14]. Niranjan prepared poly( $p$-xylylene) nanofilm on $\mathrm{Si}(100)$ wafer with anisotropic wetting property by using a bottom-up vapor-phase approach [18]. However, these manufacturing techniques are mainly for processing polymer or silicon materials. To the best of the authors' knowledge, research on manufacturing technique for asymmetric microstructures on metallic materials is still rare. Furthermore, the current high cost and complicated processes restrict the promotion of nature-inspired structured functional surfaces for industrial-scale production and application.

In this study, a novel, highly-efficient technique for the manufacturing of asymmetric microstructures is developed using nanosecond pulsed laser ablation followed by chemical etching. First of all, the undesired oxide and recast layers, which often result in short service life and poor surface quality, will be removed by the chemical etching process. Secondly, the asymmetric microstructures will form on the surface, which realized anisotropic superhydrophobicity. Furthermore, the direction, depth, and width of microstructures can be well controlled through setting up corresponding laser machining parameters.

\section{Work Principle of LA-CE}

The schematic of the LA-CE process is illustrated in Fig. 1. The laser pulses are firstly focused on the specimen by an objective lens, inducing microchannels on the surface of specimen. The laser pulses will be obliquely irradiated on the specimen surface due to the resultant motion of the work stage in the feed and pulsed directions and result in asymmetric ratchet-like recast layers. The laser-ablated specimen is then treated by an aqueous solution of ferric chloride hexahydrate $\left(32 \mathrm{~g} \mathrm{FeCl}_{3} \cdot 6 \mathrm{H}_{2} \mathrm{O}, 3 \mathrm{ml}\right.$ of $37 \% \mathrm{HCl}, 3 \mathrm{ml}$ of $85 \% \mathrm{H}_{3} \mathrm{PO}_{4}, 120 \mathrm{ml} \mathrm{H}_{2} \mathrm{O}$ ) to remove the oxide layer and laser-induced recast layers and to obtain periodic ratchet-like laminar structures. Finally, these specimens were dried in an oven. Before measuring the contact angle, these specimens were silanized in a vacuum oven using silane reagent $(1 H$, $1 \mathrm{H}, 2 \mathrm{H}, 2 \mathrm{H}$-perfluorooctyltriethoxysilane, 97\%, Alfa Aesar Ltd), at $100{ }^{\circ} \mathrm{C}$ for $12 \mathrm{~h}$ to reduce their surface free energies.

Furthermore, Fig. 1 also shows the images of the specimen by the laser ablation and LA-CE processes respectively. The specimen of laser ablation shows a black color due to the oxide layer laser formed in the laser ablation process. However, the specimen prepared by LA-CE process shows a similar color to the unprocessed surface.

\section{Materials and Experimental Setup}

\subsection{Laser Processing Experiment Hardware}

The laser processing experiments were carried out on a hybrid ultra-precision machine, as shown in Fig. 2a. It is equipped with a nanosecond pulsed fiber laser which has a 


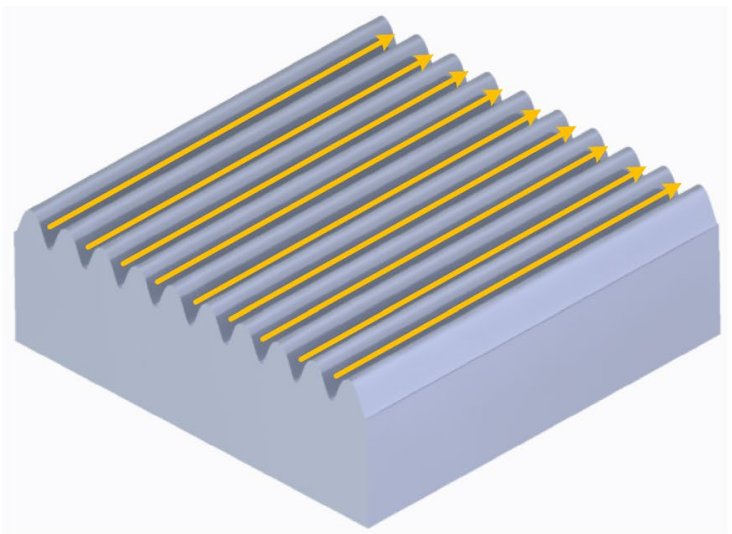

(a)

Fig. 3 Schematic of feed directions. a Unidirectional and $\mathbf{b}$ bidirectional

central emission wavelength of $1064 \mathrm{~nm}$. Figure $2 \mathrm{~b}$ is the schematic of the mechanism (reaction) of laser ablation (or chemical etching). The laser source has a nominal average output power of $20 \mathrm{~W}$, and its maximum pulse repetition rate is $200 \mathrm{kHz}$. At a pulse repetition rate of $20 \mathrm{kHz}$, the average pulse duration is $100 \mathrm{~ns}$, and the pulse energy is $1 \mathrm{~mJ}$. An achromatic doublet with a focal length of $26.054 \mathrm{~mm}$ was used to focus the laser beam. The achieved spot size is about $15 \mu \mathrm{m}$ in diameter. During laser processing operation, the laser beam passes through the lens and is focused on the specimen surface, which is mounted on a precision $\mathrm{X}-\mathrm{Y}-\mathrm{C}$ stage.

\subsection{Material and Laser Ablation Parameters}

AISI 316L stainless steel was used as the experimental material in this experiment. The stainless-steel plates were machined by a flat end mill (with a diameter of $6 \mathrm{~mm}$ ). The details of the operational conditions for the experiments are shown in Table 1. The fourth group in Table 1 is chosen as the control group to display the relationship between the directions of laser beam feed and microstructures. The schematics of unidirectional and bidirectional feed directions are shown in Fig. 3.

\section{Experimental Results and Discussion}

\subsection{Surface Morphologies and Composition}

The morphologies of specimens prepared by LA-CE process are presented in Fig. 4. In the laser ablation process, the molten materials are partially ejected from the cavity and form surface debris. Meanwhile, the oxidation reaction occurs between the molten materials and oxygen. At the

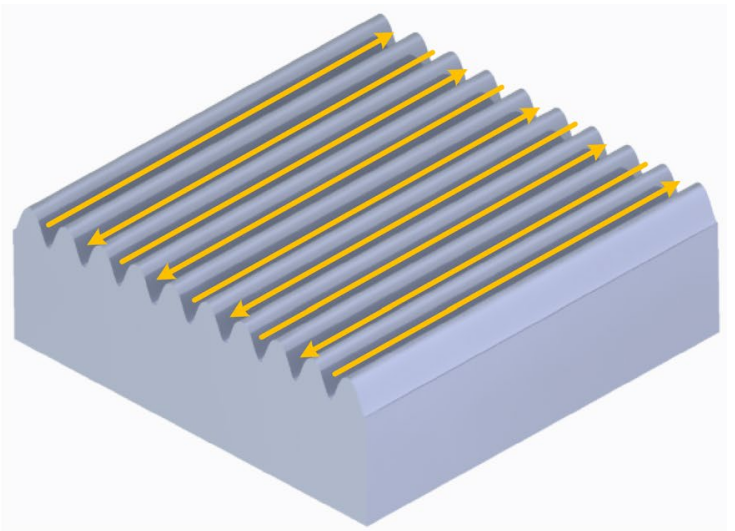

(b) end of a pulse, the heat quickly dissipates into the bulk of the work material and the oxide layers and recast layers are formed as shown in Fig. 4a.

During the chemical etching process, the oxide layer and recast layer were removed from the surface, and the laminar microstructures were formed. As shown in Fig. 4b, c, d, f, $\mathrm{g}, \mathrm{h}$, the direction of the titled microstructures is towards the laser beam feed direction. To verify the above phenomena, the specimen 4 was processed by employing bidirectional laser beam feed. As expected, bidirectional microstructures were formed on the substrate as shown in Fig. 4e. Therefore, the direction of microstructures can be well controlled by the laser beam feed direction.

At the laser power of $10 \mathrm{~W}$ (Fig. 4b), the surface morphologies are laminar periodic microstructures with clear boundaries between the adjacent rows and well separated by ridges. However, the adjacent rows of microstructures are connected when the laser power is further increased to $15 \mathrm{~W}$ and $20 \mathrm{~W}$, and no ridges are observed after the chemical etching process. This is because the increased laser power results in a larger recast layer.

As shown in high-magnification images of Fig. 4b-d, the average width of the etched microstructures increased from 20.3 to $25.2 \mu \mathrm{m}$ as the laser power increased from 10 to $20 \mathrm{~W}$, respectively. The average width of the specimen 4 (bidirectional) is $25.4 \mu \mathrm{m}$, which is more or less the same as the width of the specimen 3 (i.e., $25.2 \mu \mathrm{m}$ ), hence the laser beam feed direction does not affect the width of microstructures. At a large pitch of $50 \mu \mathrm{m}$, the width of microstructures increased from 21.4 to $31.7 \mu \mathrm{m}$ when the laser power increased from 10 to $20 \mathrm{~W}$, as shown in Fig. $4 \mathrm{f}-\mathrm{h}$. Moreover, it can be observed that the depth of microstructures shows an increasing trend with increasing laser power.

Furthermore, increasing pitch from 25 to $50 \mu \mathrm{m}$ results in a significant change of morphology. At a large pitch of 
Fig. 4 SEM images of specimens: low-magnification (left) and high-magnification (right) a specimen 1 with a pitch of $25 \mu \mathrm{m}$ after laser ablation; b-h surface morphologies of specimens 1 to 7 manufactured by LA-CE process
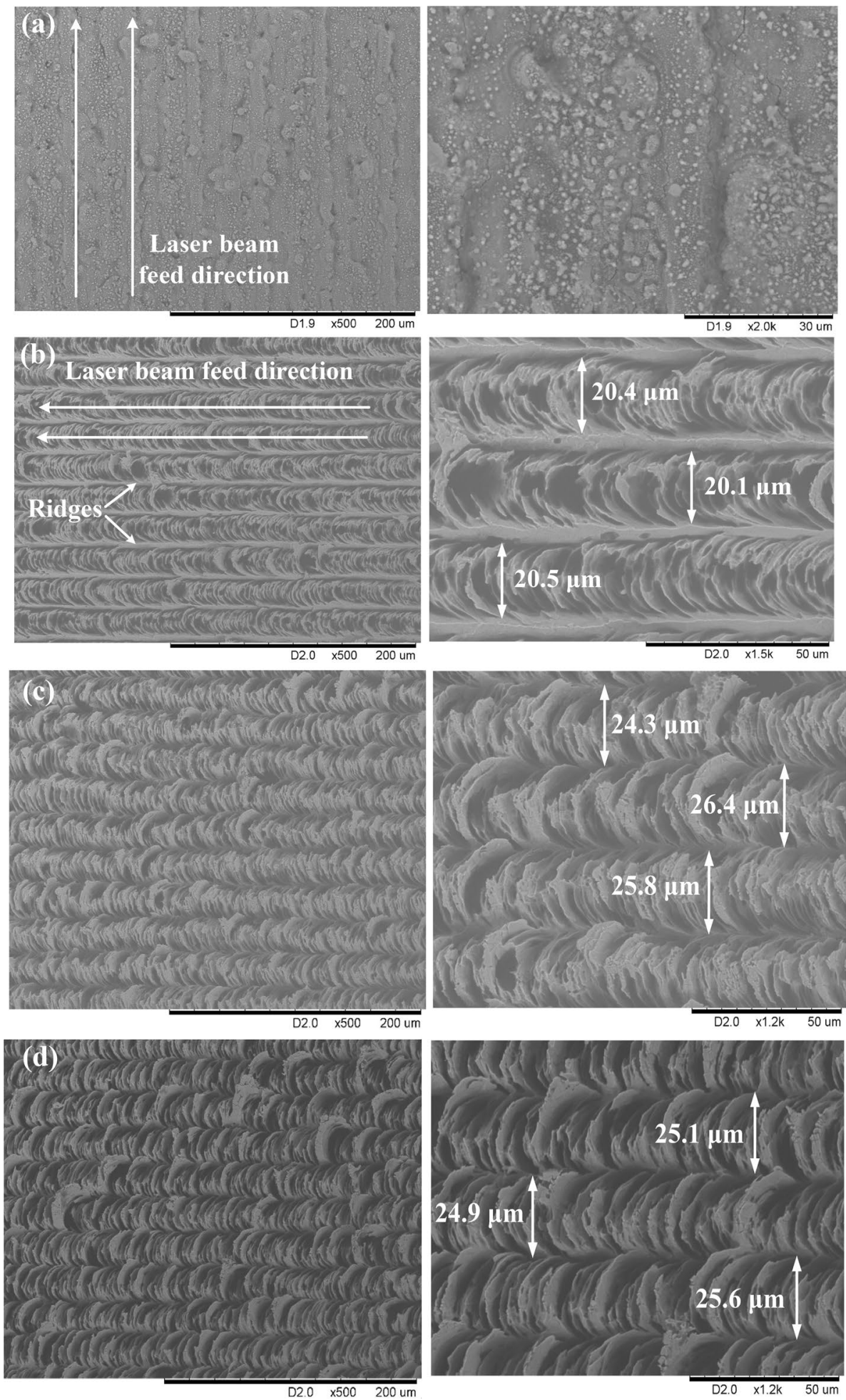

$50 \mu \mathrm{m}$ (i.e., Fig. $4 \mathrm{~g}, \mathrm{~h}$ ), the microstructures in different rows have clear boundaries and are well separated by ridges, while different rows of microstructures are closely connected at a small pitch of $25 \mu \mathrm{m}$, as shown in Fig. $4 \mathrm{c}$, d. Thus, the width and depth of microstructures are determined by both the pitch of microstructures and laser power.
Figure 5 shows X-ray diffraction patterns (XRD) of smooth surface, laser ablated surface, and surface fabricated by the LA-CE process of AISI 316L stainless steel. In Fig. 5a, four sharp diffraction peaks correspond to the XRD pattern of austenite and one peak for ferrite. For the laserablated surface, it was found that austenite, $\mathrm{Fe}_{3} \mathrm{O}_{4}$ and $\mathrm{Fe}_{2} \mathrm{O}_{3}$ 
Fig. 4 (continued)
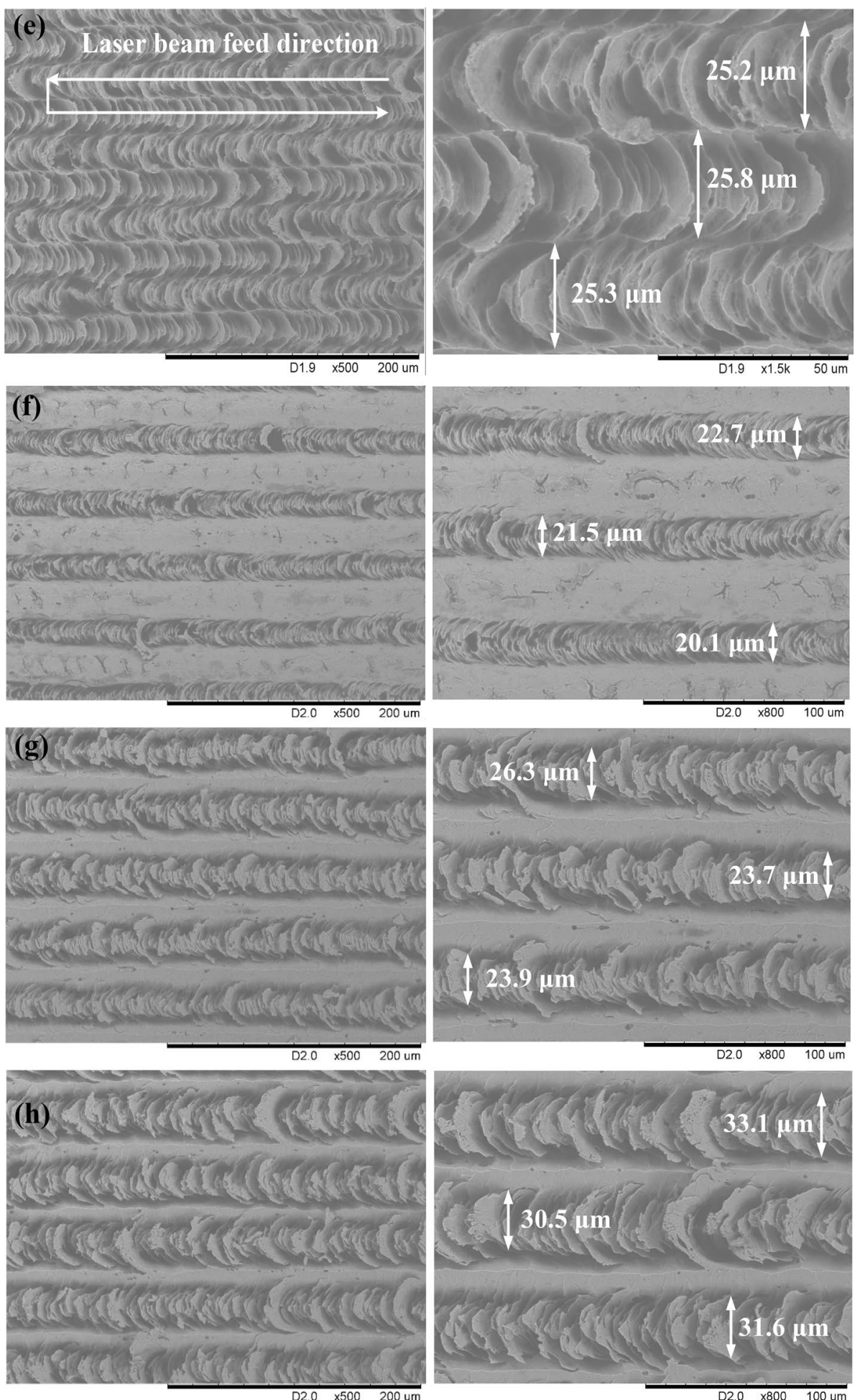

were recognized on the XRD pattern (Fig. 5b). Figure 5c shows that there is no iron oxide on the surface machined by the LA-CE process.

The above results proved that the main components of the oxide layer are $\mathrm{Fe}_{3} \mathrm{O}_{4}$ and $\mathrm{Fe}_{2} \mathrm{O}_{3}$ on the specimen. Hence, the details of the chemical reaction are expressed as:

$$
\begin{aligned}
& \mathrm{Fe}_{3} \mathrm{O}_{4}+8 \mathrm{HCl} \rightarrow \mathrm{FeCl}_{2}+2 \mathrm{FeCl}_{3}+4 \mathrm{H}_{2} \mathrm{O} \\
& 3 \mathrm{Fe}_{3} \mathrm{O}_{4}+8 \mathrm{H}_{3} \mathrm{PO}_{4} \rightarrow 6 \mathrm{FePO}_{4}+\mathrm{Fe}_{3}\left(\mathrm{PO}_{4}\right)_{2}+12 \mathrm{H}_{2} \mathrm{O} \\
& \mathrm{Fe}_{2} \mathrm{O}_{3}+6 \mathrm{HCl} \rightarrow 2 \mathrm{FeCl}_{3}+3 \mathrm{H}_{2} \mathrm{O}
\end{aligned}
$$


Fig. 5 X-ray diffraction pattern of AISI 316L stainless steel at different processes. a Smooth surface, $\mathbf{b}$ laser ablation, and $\mathbf{c}$ LA-CE process

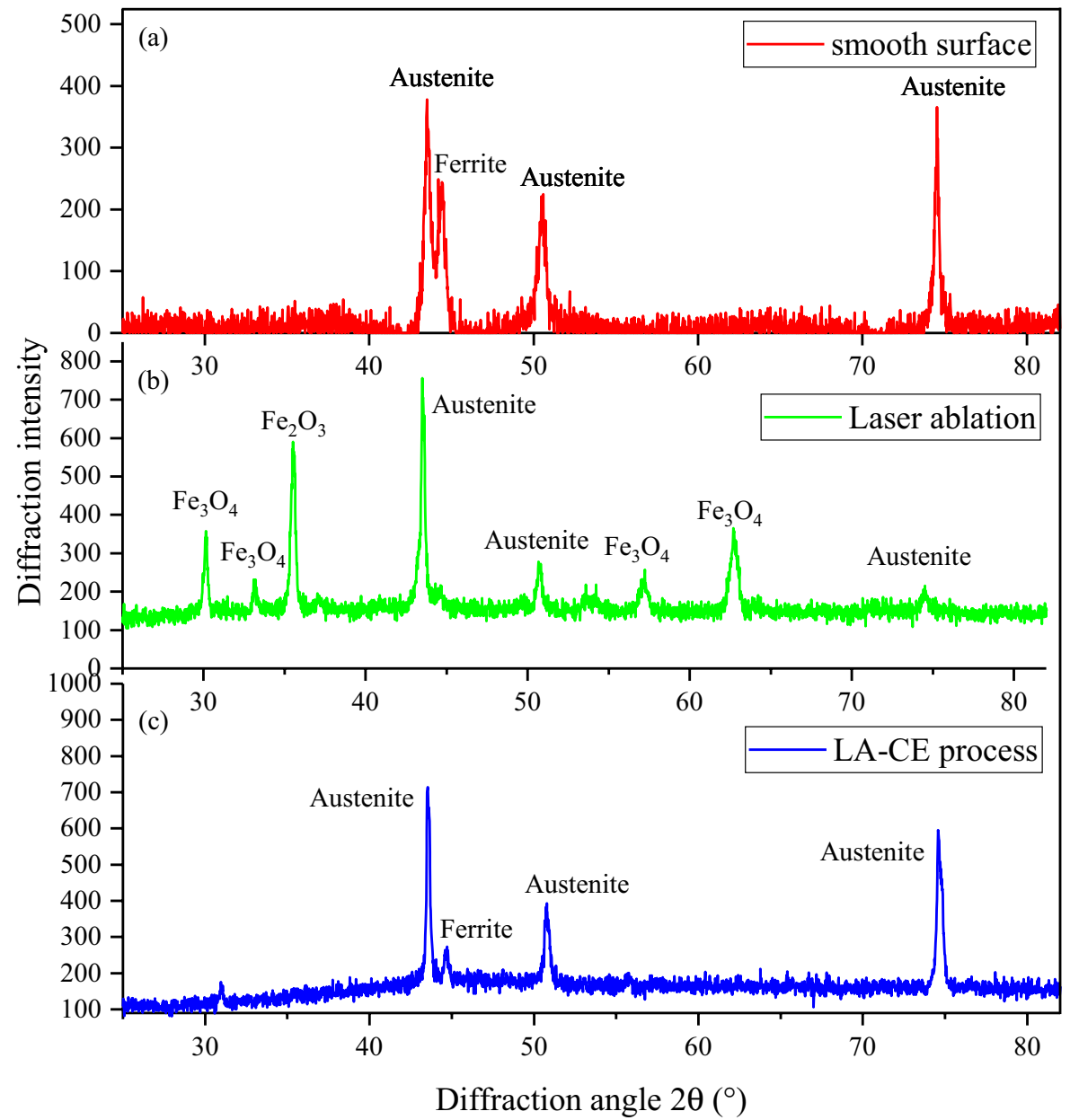

$\mathrm{Fe}_{2} \mathrm{O}_{3}+2 \mathrm{H}_{3} \mathrm{PO}_{4} \rightarrow 2 \mathrm{FePO}_{4}+3 \mathrm{H}_{2} \mathrm{O}$

$\mathrm{Fe}+2 \mathrm{FeCl}_{3} \rightarrow 3 \mathrm{FeCl}_{2}$

As shown in the above equations, the oxide layer will react with acid to form the corresponding salt and water, and the iron will react with ferric chloride to produce iron (II) chloride simultaneously.

\subsection{Anisotropic Superhydrophobicity of Specimens}

Figure 6 a shows the captured images of water droplets on different specimens. Figure $6 \mathrm{~b}$ shows the variation of the contact angle of the machined surfaces versus pitches obtained under different laser power. The contact angle for the specimens with the pitch of $25 \mu \mathrm{m}$ are similar when the average laser power increased from 10 to $20 \mathrm{~W}$, which are $156.1^{\circ}, 155.6^{\circ}$, and $158.2^{\circ}$ respectively. However, increasing laser power will cause the contact angle to increase significantly from $137.6^{\circ}$ to $157.1^{\circ}$ for specimens with a larger pitch of $50 \mu \mathrm{m}$. The larger laser power results in a larger laser ablation area and smaller unstructured region. Moreover, it further leads to a smaller solid-liquid contact area, which is beneficial to the hydrophobicity of the specimen.

Figure 7 shows the anisotropic superhydrophobicity of Specimen 3. A 5- $\mu$ l water droplet has a rolling-off angle of $7^{\circ}$ when the dip direction of the specimen is the same as the laser beam feed direction. However, the water droplet shows a pinning state in the opposite direction, due to the taper-ratchet structure.

\subsection{Discussion}

The phenomenon of the directional move of a water droplet along the tilt orientation of microstructures has been found and theoretically explained in some research [11, 18, 19]. Extrand found that liquid drops tend to move preferentially in the direction of dip on asymmetric sawtooth surfaces [19]. The theoretical analysis results suggest that the increasing feature asymmetry will result in an increase in the difference between the retention force in one direction versus the other [19]. 

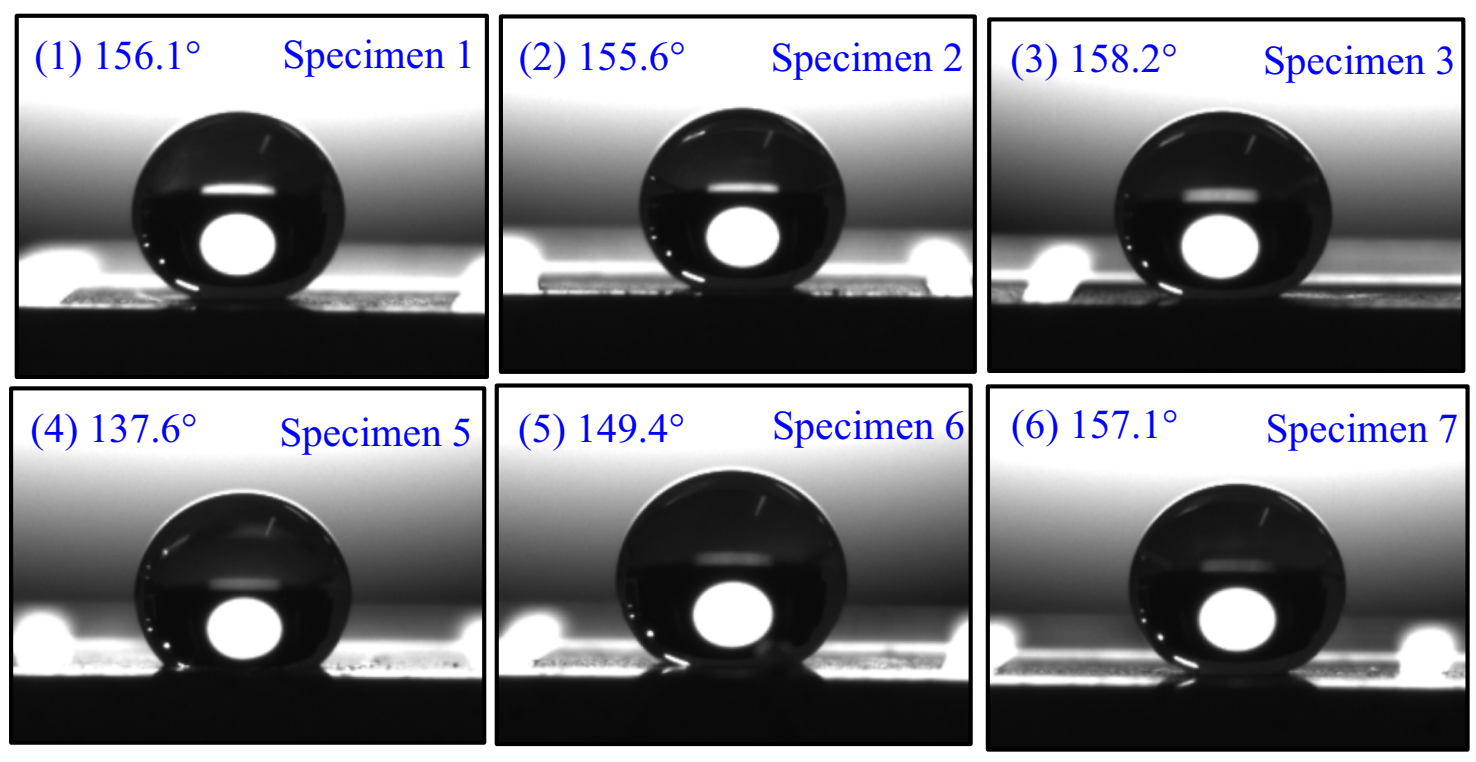

(a)

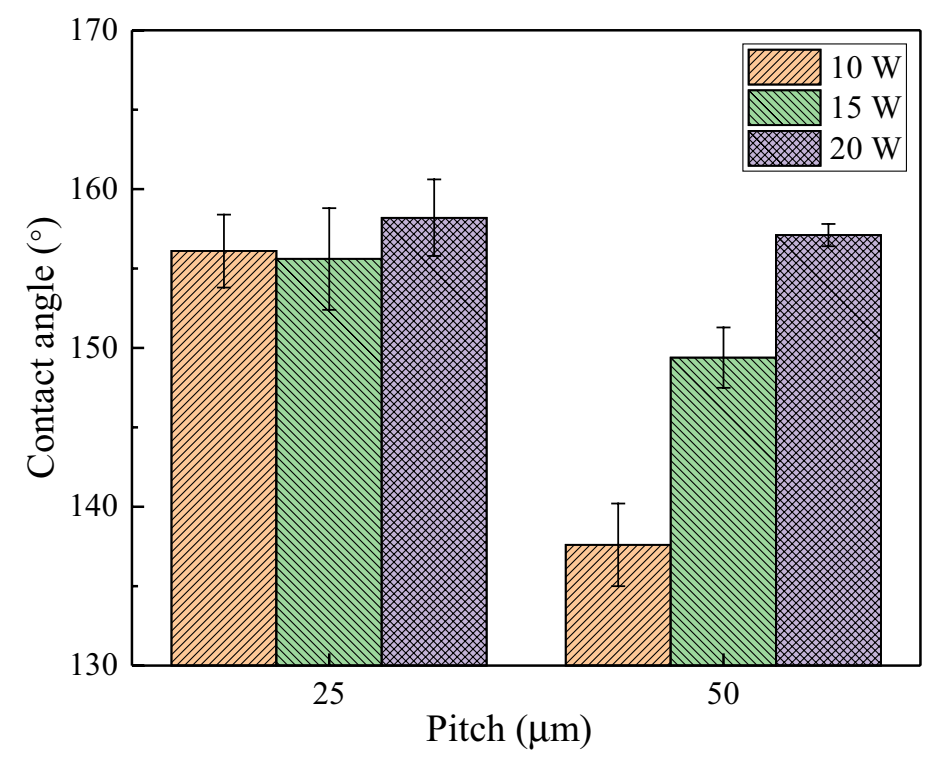

(b)

Fig. 6 a Captured images of water droplets. b Variation of contact angle versus pitches for different laser power

Figure 8a shows the wetting state of a water droplet for different dip directions. For a given tilt angle $\alpha$, there is a downslope gravitational force $F_{\mathrm{d}}$ on the water droplet:

$F_{\mathrm{d}}=F_{\mathrm{g}} \sin \alpha=\rho g V \sin \alpha$

where $F_{\mathrm{g}}$ is the gravity of water droplet, $\rho$ is the density of water, $g$ is the gravitational acceleration, and $V$ is the volume of water droplet.
The retention force of substrate to water droplet in two directions are $F_{1}$ and $F_{2}$, which is the consequence of contact angle hysteresis and causes droplets to adhere to surfaces [18].

$F_{1}$ is the retention force when the downslope gravitational force $F_{\mathrm{d}}$ is opposite to the laser beam feed direction. $F_{2}$ is the retention force when the downslope gravitational force $F_{\mathrm{d}}$ is in the same direction as the laser beam feed. 


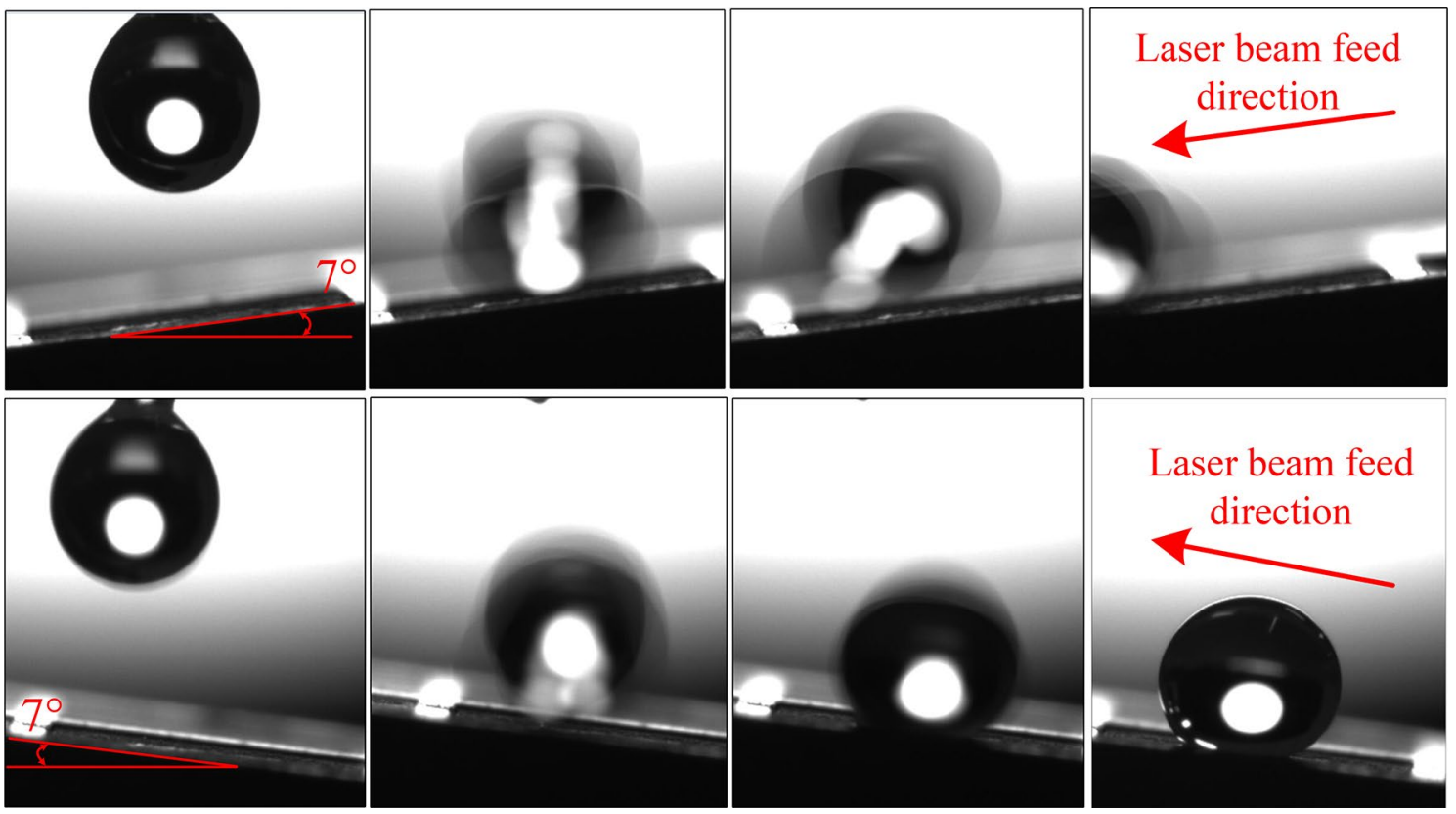

Fig. 7 Anisotropic superhydrophobicity of Specimen 3

Fig. 8 a Wetting states of water droplet at different dip directions. b Retention force of asymmetric feature with rise angles of $\omega_{1}$ and $\omega_{2}$

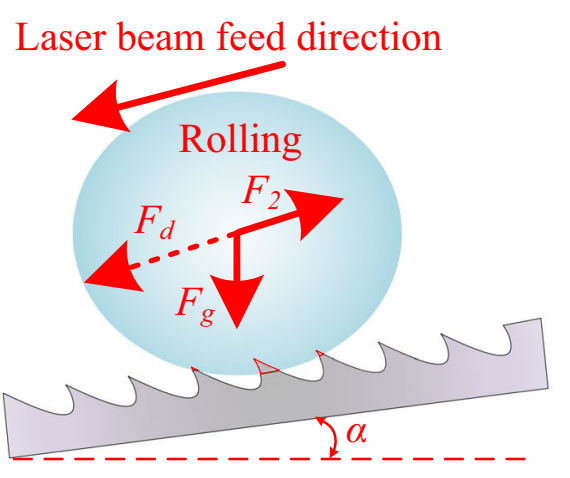

Laser beam feed direction

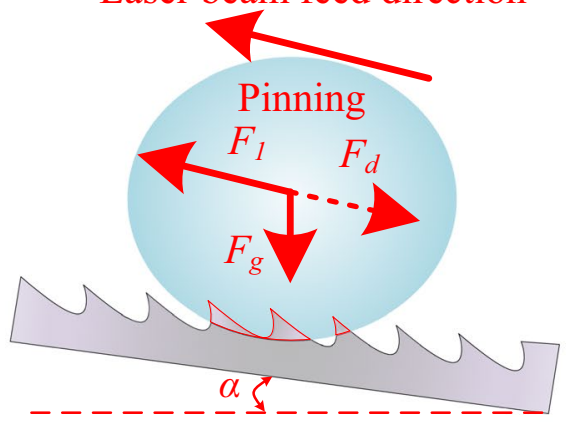

(a)

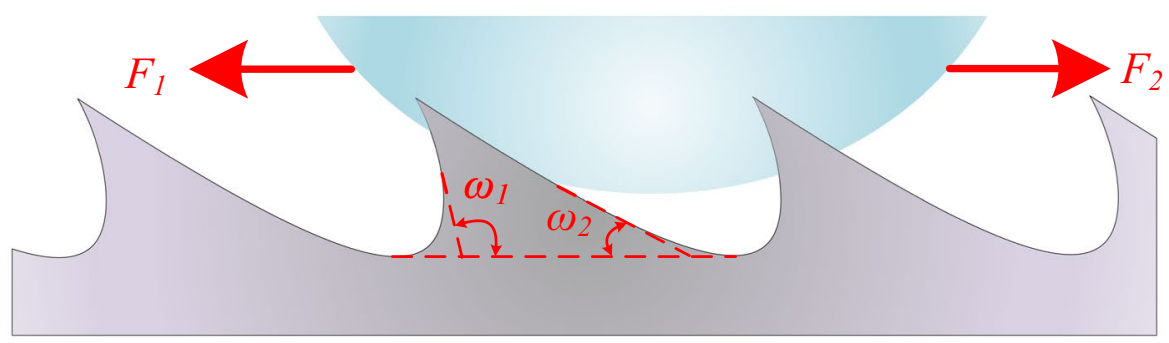

(b) 
For a given tilt angle $\alpha$, the downslope gravitational force $F_{\mathrm{d}}$ is greater than the retention force $F_{1}$ or $F_{2}$, which is a necessary condition for rolling off from the substrate of the water droplet. Figure $8 \mathrm{~b}$ illustrated the asymmetric feature with rising angles of $\omega_{1}$ and $\omega_{2}$. The ratio of retention force $F_{1}$ and $F_{2}$ can be expressed as $[18,19]$ :

$F_{1} / F_{2} \sim \frac{\sin \left(\omega_{1}+\frac{1}{2} \Delta \theta\right)}{\sin \left(\omega_{2}+\frac{1}{2} \Delta \theta\right)}$

$\Delta \theta=\theta_{\mathrm{ADV}}-\theta_{\mathrm{REC}}$

where $\Delta \theta$ is the differential of the advancing angle $\theta_{\mathrm{ADV}}$ and receding angle $\theta_{\mathrm{REC}}$.

As shown in Fig. 8 b, $\omega_{1}$ is greater than $\omega_{2}$; hence, the retention force $F_{1}$ is larger than $F_{2}$.

The downslope gravitational force $F_{\mathrm{d}}$ is easier to overcome the retention force $F_{2}$ than $F_{1}$. Hence, the water droplet easily rolls off the surface when $F_{\mathrm{d}}$ is in the same direction as the laser beam feed.

\section{Conclusions}

In this paper, a new sequential manufacturing process, named LA-CE, was successfully developed to generate anisotropic superhydrophobic structures on AISI 316L stainless steel. The conclusions are drawn as follows:

1. Laser beam feed direction will determine the direction of the generated microstructures by LA-CE.

2. Both the width and depth of the generated microstructures increase with increasing laser power. This is because the large laser power results in a large influence zone, and in consequence, the ridges of adjacent microstructure disappear. However, increasing the pitch of microstructures will cause the ridges to reappear.

3. The specimen with a pitch of $25 \mu \mathrm{m}$ machined at a laser power of $20 \mathrm{~W}$ has a maximum contact angle of $158.2^{\circ}$. Furthermore, with a dip angle of $7^{\circ}$, this specimen shows strong anisotropic superhydrophobicity, as the droplet easily rolls off the surface in the laser beam feed direction; however, it is pinned tightly in the opposite direction.

Acknowledgements This research was undertaken in the context of MICROMAN project ("Process Fingerprint for Zero-defect Netshape MICROMANufacturing", http://www.microman.mek.dtu.dk/). MICROMAN is a European Training Network supported by Horizon 2020, the EU Framework Programme for Research and Innovation (Project ID: 674801). The authors would also gratefully acknowledge the financial support from the EPSRC (EP/K018345/1) and Royal
Society-NSFC International exchange scheme (IE141422 and IECl NSFC1181474) for this research.

Data Statement All data underpinning this publication are openly available from the University of Strathclyde KnowledgeBase at https ://doi.org/10.15129/a4a6a68a-dfc0-47df-8cdd-04db6207d927.

Open Access This article is distributed under the terms of the Creative Commons Attribution 4.0 International License (http://creativeco mmons.org/licenses/by/4.0/), which permits unrestricted use, distribution, and reproduction in any medium, provided you give appropriate credit to the original author(s) and the source, provide a link to the Creative Commons license, and indicate if changes were made.

\section{References}

1. Bixler GD, Bhushan B (2013) Fluid drag reduction and efficient self-cleaning with rice leaf and butterfly wing bioinspired surfaces. Nanoscale 5:7685-7710. https://doi.org/10.1039/c3nr0 $1710 \mathrm{a}$

2. Mei H, Luo D, Guo P, Song C, Liu C, Zheng Y, Jiang L (2011) Multi-level micro-/nanostructures of butterfly wings adapt at low temperature to water repellency. Soft Matter 7:10569-10573. https ://doi.org/10.1039/c1sm06347b

3. Peng W, Hu X, Zhang D (2011) Bioinspired fabrication of magneto-optic hierarchical architecture by hydrothermal process from butterfly wing. J Magn Magn Mater 323:2064-2069. https://doi. org/10.1016/j.jmmm.2011.03.015

4. Liu C, Ju J, Zheng Y, Jiang L (2014) Asymmetric ratchet effect for directional transport of fog drops on static and dynamic butterfly wings. ACS Nano 8:1321-1329. https://doi.org/10.1021/nn404 $761 \mathrm{q}$

5. Zheng Y, Gao X, Jiang L (2007) Directional adhesion of superhydrophobic butterfly wings. Soft Matter 3:178-182. https://doi. org $/ 10.1039 / \mathrm{b} 612667 \mathrm{~g}$

6. Cui Y, Li D, Bai H (2017) Bioinspired smart materials for directional liquid transport. Ind Eng Chem Res 56:4887-4897. https:// doi.org/10.1021/acs.iecr.7b00583

7. Wang D, Zhang X, Zhang D (2018) Fabrication of a peristome surface structure of Nepenthes alata by elliptical vibration cutting. Nanomanufacturing Metrol 1:209-216. https://doi.org/10.1007/ s41871-018-0022-y

8. Guo Z, Liu W, Su BL (2011) Superhydrophobic surfaces: from natural to biomimetic to functional. J Colloid Interface Sci 353:335-355. https://doi.org/10.1016/j.jcis.2010.08.047

9. Guo Z, Liu W (2007) Biomimic from the superhydrophobic plant leaves in nature: binary structure and unitary structure. Plant Sci 172:1103-1112. https://doi.org/10.1016/j.plantsci.2007.03.005

10. Yoon Y, Kim D, Lee J-B (2014) Hierarchical micro/nano structures for super-hydrophobic surfaces and super-lyophobic surface against liquid metal. Micro Nano Syst Lett 2:1-18. https://doi. org/10.1186/s40486-014-0003-X

11. Guo P, Zheng Y, Liu C, Ju J, Jiang L (2012) Directional sheddingoff of water on natural/bio-mimetic taper-ratchet array surfaces. Soft Matter 8:1770-1775. https://doi.org/10.1039/c1sm06631e

12. Liu Y, Wang X, Fei B, Hu H, Lai C, Xin JH (2015) Bioinspired, stimuli-responsive, multifunctional superhydrophobic surface with directional wetting, adhesion, and transport of water. Adv Funct Mater 25:5047-5056. https://doi.org/10.1002/adfm.20150 1705

13. Bixler GD, Bhushan B (2012) Bioinspired rice leaf and butterfly wing surface structures combining shark skin and lotus effects. Soft Matter 8:11271-11284. https://doi.org/10.1039/c2sm26655e 
14. Song F, Su H, Han J, Zhang D, Chen Z (2009) Fabrication and good ethanol sensing of biomorphic $\mathrm{SnO}_{2}$ with architecture hierarchy of butterfly wings. Nanotechnology. https://doi. org/10.1088/0957-4484/20/49/495502

15. Hancock MJ, Sekeroglu K, Demirel MC (2012) Bioinspired directional surfaces for adhesion, wetting, and transport. Adv Funct Mater 22:2223-2234. https://doi.org/10.1002/adfm.201103017

16. Kwak MK, Jeong HE, Il Kim T, Yoon H, Suh KY (2010) Bioinspired slanted polymer nanohairs for anisotropic wetting and directional dry adhesion. Soft Matter 6:1849-1857. https://doi. org/10.1039/b924056j

17. Hasan RMM, Luo X (2018) Promising lithography techniques for next-generation logic devices. Nanomanufacturing Metrol 1:67-81. https://doi.org/10.1007/s41871-018-0016-9

18. Malvadkar NA, Hancock MJ, Sekeroglu K, Dressick WJ, Demirel MC (2010) An engineered anisotropic nanofilm with unidirectional wetting properties. Nat Mater 9:1023-1028. https://doi. org/10.1038/nmat2864

19. Extrand CW (2007) Retention forces of a liquid slug in a rough capillary tube with symmetric or asymmetric features. Langmuir 23:1867-1871. https://doi.org/10.1021/la0625289

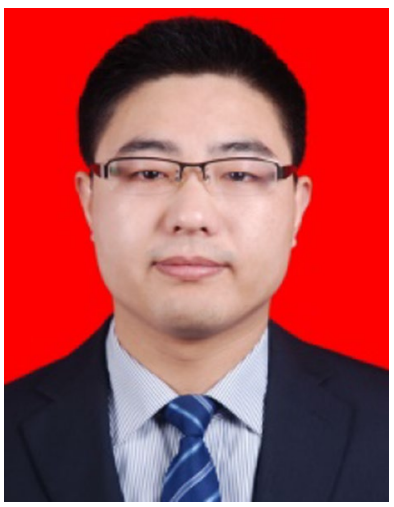

Yukui Cai is a Marie SklodowskaCurie Early Stage Research Fellow in the Centre for Precision Manufacturing at the University of Strathclyde. Yukui completed his $\mathrm{PhD}$ at Shandong University and his undergraduate studies at Qingdao University of Science and Technology. His research interests lie in the area of microfluidic, micromachining and laser machining, ranging from theory to design and implementation.

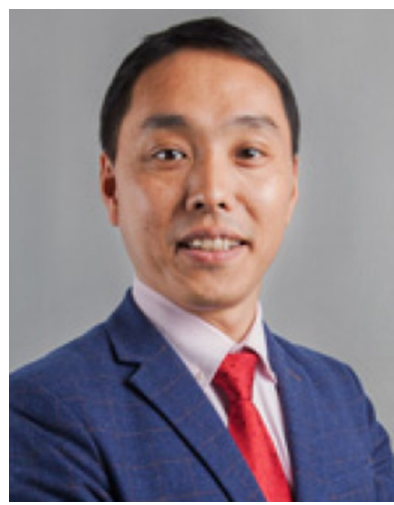

Dr. Zongwei Xu is Associate Professor (Tenure track) from College of Precision Instrument \& Opto-electronics Engineering, Tianjin University, China. Dr. $\mathrm{Xu}$ got his $\mathrm{PhD}$ degree in 2007 from Harbin Institute of Technology, China. His principle research interests include: 1 . Fundamental research on Wide Band Gap (WBG) semiconductor materials: defect physics, optical spectroscopy characterization 2. Micro/nanofabrication using Focused ion Beam (FIB): techniques, novel method and functional device development 3. Nanofabrication mechanism: atomistic simulation, in-situ SEM characterization, Raman spectroscopy.

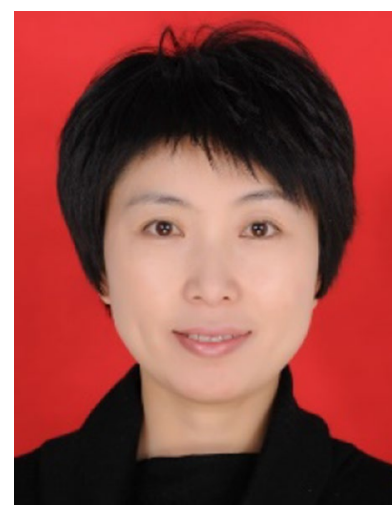

Hong Wang Associate Professor, Doctor (Tianjin University), Master Tutor, School of Materials Science and Engineering, Tianjin Polytechnic University. She mainly engaged in inorganic catalytic membrane materials, organic electrochemical synthesis, electrochemical research and development of electro-catalytic membrane reactor, sewage treatment, and etc. In recent years, innovative achievements were got from the R\&D and application of electro-catalytic membrane reactor.

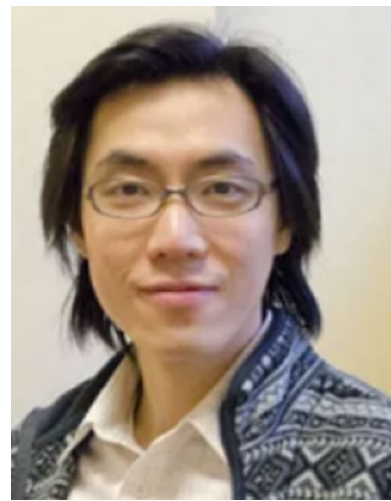

Dr. King Hang Aaron Lau is a senior Lecturer in Pure and Applied Chemistry at University of Strathclyde. His research aims to establish the design rules for creating synthetic polymers and nanostructures that mimic the structure and function of natural biomolecules.

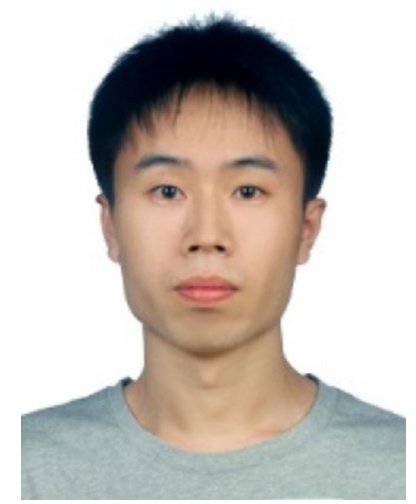

Fei Ding is currently a PhD student in mechanical enginnering from University of Strathclyde, UK. He received B.S. and M.S. degrees in Harbin Institude of Technology, Harbin, China in 2013 and 2015. His research interests are ultra-precision machine tool design and precicion motion control. 


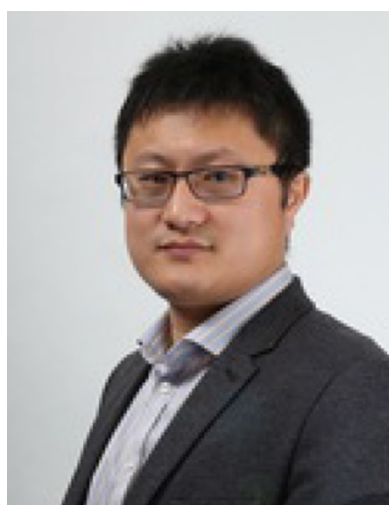

Dr. Jining Sun received his BSc degree (Physics) in 2004 and MSc degree (Particle Physics) in 2007, both from Peking University, China. In 2012 he obtained his $\mathrm{PhD}$ degree from Heriot-Watt University. Now he is an assistant professor in School of Engineering and Physical Sciences at Heriot-Watt University, Edinburgh. His research interests include micro/nano-manufacturing, and cross-scale machining technologies. He has over 40 publications in peer-reviewed journals and international conferences, 1 invited book chapter. He has extensive industrial related experiences and has been involved in several prestige industrial projects. His contribution to the community has been recognized by Institution of Mechanical Engineers (IMechE) and was awarded the Ludwig Mond Prize in 2015.

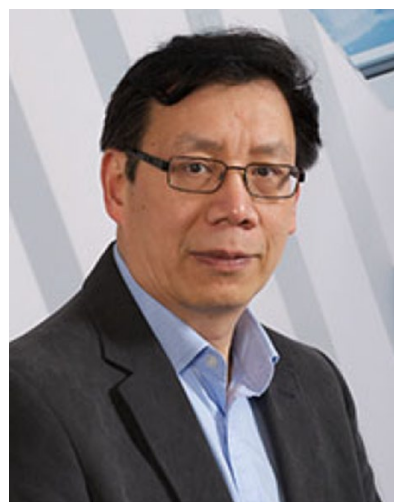

Yi Qin is a Professor in Manufacturing Technology and Systems, Director of the Centre for Precision Manufacturing at the University of Strathclyde, Fellow of The Institution of Mechanical Engineers, Editor-in-Chief of the Journal of Manufacturing Review, Associate Editor of the International Journal of Lightweight Materials and Manufacture, Advisor to the International Commercial Magazine "MicroManufacturing". His interests in research and technological development are in the field of Materials Forming and Precision/Micro-Manufacturing, and he has published over 200 technical papers on the relevant topics in those fields.

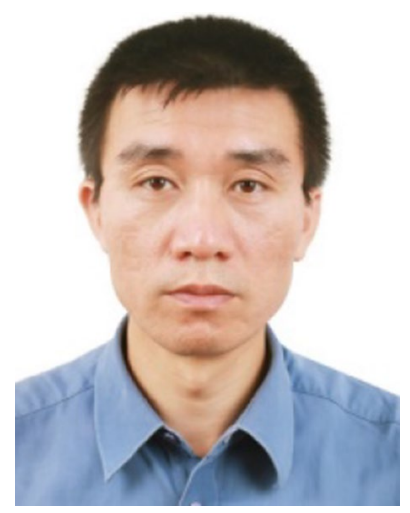

Xichun Luo is a Professor in ultra precision manufacturing and technical director of Centre for Precision Manufacturing (CPM) at the University of Strathclyde (Glasgow). He is a Fellow of the International Society for Nanomanufacturing and an editor for Proceeding of IMechE Part C: Journal of Mechanical Engineering Science, Journal of Micromanufacturing and Mechanical Sciences. He also sits in the editorial board for Micromachines, Nanomanufacturing and Metrology. His research interests include ultra precision machining brittle materials, freeform machining, precision motion control, hybrid micromachining and FIB nanomanufacturing. 